\title{
Relevance of sociodemographic characteristics in care of HIV reactive pregnant women in the context of upscaled antiretrovial therapy in India
}

\author{
Padmaja Y. Samant ${ }^{1 *}$, Juhi J. Puri²
}

\begin{abstract}
${ }^{1}$ Department of Obstetrics and Gynecology, Seth Gordhandas Sunderdas Medical College, Mumbai, Maharashtra, India

${ }^{2}$ Department of Obstetrics and Gynecology, Government Medical College, Aurangabad, Maharashtra, India
\end{abstract}

Received: 02 July 2017

Accepted: 29 July 2017

\section{*Correspondence:}

Dr. Padmaja Y. Samant,

E-mail: padmaja_mavani@yahoo.co.in

Copyright: (C) the author(s), publisher and licensee Medip Academy. This is an open-access article distributed under the terms of the Creative Commons Attribution Non-Commercial License, which permits unrestricted non-commercial use, distribution, and reproduction in any medium, provided the original work is properly cited.

\begin{abstract}
Background: The burden of HIV and AIDS comes with social, monetary and health related consequences. HIV is reported to be a pandemic, but the maximum burden of the disease is in the low and middle income $\backslash$ countries. In obstetric context, sociodemographic factors influence health seeking, compliance and adherence to the advised regimen. These determine vertical transmission. Present study was undertaken to study the demographic characteristics among pregnant and postpartum HIV positive women, to study the high risk obstetric conditions, morbidities and obstetric outcome, among the women, to study the neonatal outcomes among HIV reactive women and to study the postnatal choices and compliance in these women.

Methods: The study was conducted after approval from the institutional ethics committee. All antenatal patients delivering at the institute in the one and a half year of study duration, who consented to be a part of the study, were enrolled in the study. The mother-baby pair was followed up for six weeks postpartum.

Results: Eighty patients formed the study cohort as per the inclusion criteria. 44\% belonged to the age group of 26-30 years. $56.2 \%$ had attended up to secondary schooling, 55\% belonged to class III of the Kuppuswamy socio-economic class, $96.2 \%$ were married. $91.2 \%$ were homemakers. $41.8 \%$ spouses were seropositive, $25.3 \%$ spouses were not willing to be tested. $75 \%$ were registered pregnancies out of which $56 \%$ had registered before 20 weeks of gestation. $25 \%$ of neonates weighed between $2.7-2.9 \mathrm{~kg}$ closely followed by those more than $3 \mathrm{~kg}$. Fifty-four patients opted for top feeding $(66.7 \%)$. Seven mother-baby pair did not follow-up.

Conclusions: Social class and educational status play a vital role in establishing awareness and ensuring the antenatal care and compliance. Empathetic, inclusive and responsive by health care providers in convincing women to get tested goes a long way.
\end{abstract}

Keywords: Antenatal Screening, ART, HIV, PPTCT, Socio-demographic characteristics

\section{INTRODUCTION}

HIV was discovered more than twenty years ago and yet there is no cure found for the disease. The burden of the disease is in the form that it has affected most commonly the reproductive and productive population of the society. By middle of 2016, a total of 36.7 million (34.0 million39.8 million) people were living with HIV/AIDS, out of which, 2,100,000 (1,700,000-2,600,000) lived in India, out of these figures about 790,000 (660,000-960,000) 
women of reproductive age group were living with HIV/AIDS. ${ }^{1,2}$ Mother to Child transmission occurs vertically. There is possibility of transmission antenatally, during labor and delivery and postnatally during breast feeding. If mothers are not detected and treated, 15- $25 \%$ of babies get infected with HIV during pregnancy and birth and more $20 \%$ may get infected through breastfeeding. ${ }^{3}$ HIV in women of reproductive age group should be tackled in order to reduce the burden of the disease among children. It is not only useful for maternal health but will also help prevent the infection in partners if they are negative. Socio-demographic factors of women attending the clinics are important in determining the treatment acceptance, follow-up, their capacity to understand the gravity of the situation and the need to comply with the treatment. Poor pregnant women have triple jeopardy: poverty, pregnancy and gender based discrimination including violence that they face in personal and family relationships.

Stigmatisation by society as well as health systems drives them to hide their status or to not get tested at all. A sense of maternal obligation makes them opt for giving top feeds risking the neonate's life. Ignorance and access barrier risk infant lives due to infectious diseases transmitted through unsafely prepared feeds. Delays in detecting these infections and starting start of ART cause deaths of the exposed infants.

In India, anti-retroviral therapy option $\mathrm{B}+$ i.e. lifelong triple drug therapy has been rolled out for HIV+ve pregnant women for their own and their offsprings' health so that these children have the dual advantage of reduced vertical transmission as well as protection afforded by breast feeding. ${ }^{4}$ Giving top feeds to babies below 6 months risks their lives even if they remain seronegative. ${ }^{5}$ With increasing availability of antiretroviral drugs and possibilities of prolongation of quality life, the health care workers are known to feel more positive towards interventions. ${ }^{6}$ Empathetic health care providers who keep track of their patients' compliance may be able to motivate patients to participate more actively in their own management. This study of sociological factors and the demographic characteristics in assessing the care obtained by HIV positive pregnant women attempts to examine their impact on outcomes and possibility of improvement in strategies that would help in elimination of disease.

Present study was undertaken to study the demographic characteristics among pregnant and postpartum HIV positive women, to study the high risk obstetric conditions, morbidities and obstetric outcome, among the women, to study the neonatal outcomes among HIV reactive women and to study the postnatal choices and compliance in these women.

Present study was undertaken to study the demographic characteristics among pregnant and postpartum HIV positive women, to study the high risk obstetric conditions, morbidities and obstetric outcome, among the women, to study the neonatal outcomes among HIV reactive women and to study the postnatal choices and compliance in these women.

\section{METHODS}

This was a retro-prospective, observational study done at a tertiary care referral center.

The study was carried on all the consenting women who were HIV positive and who delivered in the urban tertiary care institute in the duration of one year and nine months. A total of 11,621 patients had delivered in the duration of case study, out of which 84 were HIV positive. Eighty patients formed the study cohort as per the inclusion criteria.

\section{Social and demographic variables}

The social and demographic characteristics studied were, age, educational qualification, maternal occupation, occupation of spouse, social class according to Kuppuswamy scale, marital status, sero-status of the spouse, antenatal registration of pregnancy, birth weight, sex of the baby, mode of feeding opted for, and follow up for 6 weeks.

Eighty-four HIV positive women delivered in the urban tertiary care institute during the period of study, out of which two did not consent for the study, there was one maternal death, and the fourth one had post-partum psychosis and hence was not able to give a valid consent. Thus 80 patients were taken into study.

\section{Inclusion Criteria}

All HIV positive pregnant women whether registered at the study institute or referred from some other hospital, delivering at the study hospital, diagnosed in preconception, antenatal, intrapartum, or post-partum period and who were willing to consent for the study were included in the cohort

\section{Methodology}

- After valid, informed, written consent, demographic information was collected from participant women. In prospective cases follow up was maintained till 6 weeks postpartum when the mother and baby come for their first follow up for early infant diagnosis.

- In women enrolled after birth, after consent, their antepartum details and birth records were noted.

\section{Statistical analysis}

This study being a retro-prospective observational study, simple statistical calculations were performed, using percentages and descriptive statistics. The results were tabulated and put on figures for easier illustration 
purposes. The statistical analysis includes data representation in tabular format depicting the different parameters and their distribution.

\section{RESULTS}

The participants in the cohort belonged to age groups as follows, $11 \%$ women were less than 20 years of age, $27 \%$ were aged 21 to 25 years, $44 \%$ were aged 26-30 years, $15 \%$ were between 31 to 35 and $3 \%$ population was above 35 years. Of all the patients, 77 were married, 2 were unmarried and one was a widow. The widow was lost to follow-up.
Table 1: Educational status.

\begin{tabular}{|lll|}
\hline Educational status & Number & $\%$ \\
\hline Illiterate & 17 & 21.2 \\
\hline Primary & 7 & 8.8 \\
\hline Secondary school & 45 & 56.2 \\
\hline Graduate & 11 & 13.8 \\
\hline Total & 80 & 100 \\
\hline
\end{tabular}

Maximum population was educated up to secondary school around $56.2 \%$ of the cohort.

Table 2: Characteristics of the socially and economically disadvantaged class.

\begin{tabular}{|c|c|c|c|c|c|c|c|c|c|c|c|}
\hline \multirow{2}{*}{ Education } & \multicolumn{5}{|c|}{ Occupation } & \multirow[t]{2}{*}{ Spouse status } & \multicolumn{5}{|c|}{ Antenatal care } \\
\hline & IV & III & & IV & III & & IV & III & & IV & III \\
\hline Illiterate & 7 & 10 & homemakers & 16 & 43 & $\begin{array}{l}\text { Unwilling to get } \\
\text { tested }\end{array}$ & 8 & 15 & First trimester & 5 & 6 \\
\hline $\begin{array}{l}\text { Primary } \\
\text { education }\end{array}$ & 4 & 3 & Working & 2 & 1 & Concordant & 8 & 16 & Second trimester & 5 & 27 \\
\hline $\begin{array}{l}\text { Secondary } \\
\text { education }\end{array}$ & 7 & 30 & & & & Dicordant & 1 & 13 & Third trimester & 7 & 9 \\
\hline Graduate & & 1 & & & & Dead at registration & 1 & 0 & Unregistered & 1 & 2 \\
\hline Total & 18 & 44 & & 18 & 44 & & 18 & 44 & & 18 & 44 \\
\hline $\begin{array}{l}\text { Significance } \\
\text { at } p<0.05\end{array}$ & $P=($ & & & & & & & & & & .09 \\
\hline
\end{tabular}

Eighteen women in the study group belonged to the Kuppuswamy class IV of the social class, out of which 7 were illiterate, 4 attended up to primary school and 7 had attended secondary school. Sixteen of these 18 women were home makers.

Spouses of 8 of these women were not willing for partner testing for the disease. One was dead at registration. Eight of these couples were concordant while one was discordant. Five women registered in the first trimester, five in the second trimester and seven in the third trimester and one was unregistered.

Forty-four women belonged to Kuppuswamy class III, 10 were illiterate, 3 had up to primary education, and 30 had attended secondary school, and one was a graduate. Forty-three of these women were home makers. Fifteen men were not willing for partner testing, 13 couples were discordant, and 16 were concordant. Six women registered in 1st trimester, 27 women registered in 2 nd trimester, 9 women got registered in 3rd trimester, and two were unregistered.

Seven patients had been to lost follow-up, out of which 5 were illiterate. Two patients were unregistered who had lost to follow up. Eleven women belonged to Kuppuswamy class II and 7 belonged to Kuppuswamy class I. Only a total of three patients were unregistered in the study cohort.

Table 3: Parity status.

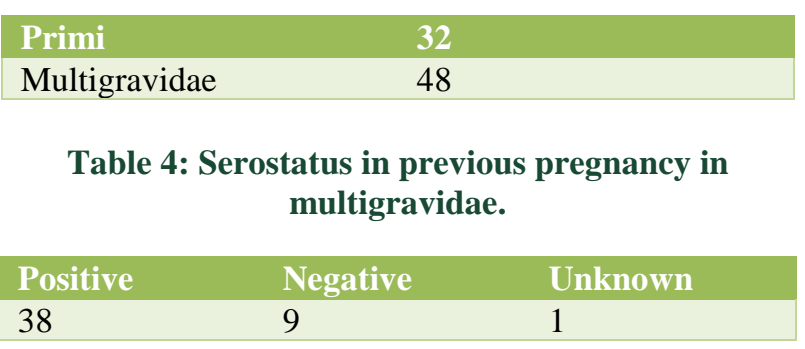

Table 5: Status of ART administration in the current pregnancy.

\begin{tabular}{|lll|}
\hline Parity & $\begin{array}{l}\text { ART taken in } \\
\text { pregnancy }\end{array}$ & No ART \\
\hline Primigravidae & 27 & 5 \\
\hline Multigravidae & 40 & 8 \\
\hline & $\mathrm{P}=0.9($ at $\mathrm{p}<0.05)$ & \\
\hline
\end{tabular}

Most patients who were not on recommended antiretroviral drugs were referred or unregistered patients except one who was registered at the tertiary care center studied but had only 2 visits. 
All of them were registered late in pregnancy. 3 were unregistered. Only 2 had more than 3 visits. Their being without recommended antiretroviral drugs is a cause for concern as a systemic lapse.

Table 6: Gestational age at registration in patients who were not ART.

\begin{tabular}{|llll|}
\hline Parity & Visits & Period of gestation at registration & Referral \\
\hline Primi & 2 & 29 weeks & Registered \\
\hline Multi & 3 & 29 weeks & Ref untested \\
\hline Primi & 3 & 30 weeks & Ref \\
\hline Multi & 0 & Unregistered, came in labor & Ref from periphery \\
\hline Multi & 0 & Unregistered, came in labor & Preterm, came in labor \\
\hline Primi & 1 & 37 weeks & Came in labor \\
\hline Multi & 2 & 32 & Referred from corporation hospital \\
\hline Multi & 2 & 36 & Lost to follow up \\
\hline Multi & 2 & 30 & Referred from corporation hospital with \\
\hline Multi & 0 & Unregistered, came in labor & Self-referral \\
\hline Primi & 1 & & Self-referral \\
\hline Multi & 10 & 18, later came in labor & Referred from private \\
\hline Primi & 9 & 16 Marol & Referred from corporation hospital \\
\hline
\end{tabular}

Table 7: Perinatal outcome and possible health system accountability in women not on antiretroviral therapy.

\begin{tabular}{|lllll|}
\hline Parity & Visits & Perinatal outcome & Accountability & Action recommended \\
\hline Primi & 2 & Died of milk aspiration on day 25 & yes & Policy review \\
\hline Multi & 3 & Alive and well & yes & Policy review \\
\hline Primi & 3 & Lost to followup & yes & Policy review \\
\hline Multi & 0 & Alive and well & no & \\
\hline Multi & 0 & Alive and well & no & Policy review \\
\hline Primi & 1 & Alive and well & yes & Policy review \\
\hline Multi & 2 & Lost to followup & yes & Policy review \\
\hline Multi & 2 & Alive and well & yes & Policy review \\
\hline Multi & 2 & FSB preterm & yes & \\
\hline Multi & 0 & Alive and well & no & \\
\hline Primi & 1 & Lost to followup & yes & Policy review \\
\hline Multi & 10 & Alive and well & yes & Policy review \\
\hline Primi & 9 & Alive and well & yes & \\
\hline
\end{tabular}

Table 8: analysis of infant deaths.

\begin{tabular}{|c|c|c|c|c|c|c|c|}
\hline Sr. no. & Weight & Maturity & CD4 & $\begin{array}{l}\text { Maternal } \\
\text { illness }\end{array}$ & $\begin{array}{l}\text { Delivery } \\
\text { complications }\end{array}$ & Feeding & AFASS criteria \\
\hline Case 1 & 1.4 & Full term & $\begin{array}{l}\text { Not } \\
\text { available }\end{array}$ & $\begin{array}{l}\text { Psoas abscess } \\
\text { in the past }\end{array}$ & IUGR & Topfed & $\begin{array}{l}\text { Fulfilled } * \text { Baby died } \\
\text { of milk aspiration }\end{array}$ \\
\hline Case 2 & 3.48 & Full term & 57 & $\begin{array}{l}\text { Pulmonary } \\
\text { Koch's }\end{array}$ & None & Topfed & Not fulfilled \\
\hline Case 3 & 2.6 & Full term & 345 & None & None & Topfed & Not fulfilled \\
\hline Case 4 & 1.1 & 31 weeks & Not done & None & None & Topfed & Not fulfilled \\
\hline Case 5 & 1.3 & FSB & 471 & $\begin{array}{l}\text { Obstetric } \\
\text { complication }\end{array}$ & IUFD & $\begin{array}{l}\text { Not } \\
\text { applicable }\end{array}$ & Not applicable \\
\hline
\end{tabular}

A total of 29 low birth weight (LBW) babies were born, one was a pair of twins, 10 births of these LBW babies was in Kuppuswamy social class IV household, 11 in class III, 4 in class II and 4 in class I. Three babies were very low birth weight (VLBW), belonged to the mothers from Kuppuswamy social class I, III, and IV. One baby was IUFD, belonged to illiterate, unregistered, street vendor born with very low birth weight of $1.33 \mathrm{~kg}$. 
Majority of patients opted for top feeding 53/80 that is $66.7 \%$ of the cohort of which 12 females belonged to Kuppuswamy class IV, 29 to class III, 7 to class II, and 5 in class I.

Infant follow-up at 6 weeks. There were 1 fetal and 4 neonatal deaths. 2 babies were shifted to Orphanages and were not tested. 7 babies and mothers were lost to follow up. 66 babies were tested at 6 weeks. They all were reported to have taken Nevirapine, and the first PCR test was negative in all of them.

\section{DISCUSSION}

\section{Age group}

In the study conducted by Goswami et al the average age of women presenting to antenatal clinic with HIV positive status ranged from 25 to 30 years in $42.71 \%$ of their study group. ${ }^{3}$ Joshi et al found that $98.8 \%$ of HIV positive mothers belonged to age group of 18-30 years. ${ }^{7}$ In this study the age group of HIV infected mother that was the most prevalent was 26-30 years forming around $44 \%$ of the study population. This is to be expected as predominant age group in pregnant women is between 20 to 30 years in most developing countries.

\section{Marital status}

In a study conducted by Fabiani et al in Uganda, marital status has not been found to have a significant association with infection of HIV. ${ }^{8}$ However, increased prevalence of HIV infection was observed in unmarried patients. The adjusted odds ratio for their study was 1.6 for unmarried antenatal patients attending the clinic. In present study married women accounted for $98.5 \%$ of study cohort. 2 patients attending the ANC clinic were unmarried constituting $2.5 \%$ of study population. One of the pregnant women was a widow whose husband had died due to AIDS during her course of antenatal period. Live in relationships are uncommon among the class of patients using public sector hospitals are not common. Sexual preferences, and number of relationships are not asked commonly. For fear of stigmatization, women may not volunteer this information.

\section{Educational qualifications}

In the study conducted by Joshi et al in Ahmedabad, western India, $35.8 \%$ of the population of HIV positive mothers were illiterate, and the rest of them had an education of primary and above. ${ }^{7}$ In a study conducted by Ojieabu et al in Nigeria, $1.2 \%$ of population in study was illiterate, without any formal education while $29.3 \%$ of respondents were educated up to secondary school, $6.5 \%$ up to primary schooling and $63 \%$ had a tertiary education. ${ }^{9}$ In an observational study conducted by Vieira et al, $9.3 \%$ of study population was illiterate. ${ }^{10}$ In present study, $21.2 \%$ were illiterate, $8.8 \%$ had primary education, $56.2 \%$ were secondary school educated comprising of the majority of study population while only $13.8 \%$ of the study population had studied beyond secondary level. Educational level differences among Kuppuswamy classes were not statistically significant.

Educational level also is an indicator of clarity of information about infectivity as indicated by Ojieabu et al. ${ }^{9}$

\section{Social class}

According to one of the study conducted in Brazil by Vieira et al, HIV prevalence was found to be more common in low socio-economic strata of the society and the authors felt the need to give more emphasis on preventive measures. ${ }^{10}$ In present case study, socioeconomic classification was done based on Kuppuswamy scale of socio-economic classification. The maximum number of patients belonged to class III amounting to $55 \%$ of case study population, while only $8.8 \%$ of the population under study belonged to class I of Kuppuswamy household. There was no statistically significant difference in spouse testing among the socioeconomic classes.

\section{Serostatus of spouse}

In the study conducted by Goswami et al over consecutive years, partners of seropositive women were counseled and tested for HIV. ${ }^{13}$ In the study conducted by Joshi et al $65.3 \%$ of the spouse were found to be HIV Reactive. ${ }^{7}$ In present study, $41.2 \%$ (33/80) out of all and ( $33 / 59) 55 \%$ out of the tested were found to be seropositive, although $25.3 \%$ (21/80) of cohort group were not willing to be examined. Marginally less positivity may be due to diverse factors including genetic.

\section{Mode of feeding in baby}

In the study conducted by Goswami et al, 95 live babies were followed up for mode of feeding in which it was found that 28 babies were breast fed while the other 67 were formula fed. ${ }^{3}$ In the study conducted by Joshi et al out of 59 live births, maximum number of patients chose methods other than exclusive breast feeding. ${ }^{7} 3.4 \%$ chose formula feeds while the rest $1.6 \%$ chose mixed pattern of feeding. In present study, out of the 80 exposed babies, $66.7 \%$ of the mothers chose formula feeds of the babies while the remaining $32 \%$ chose to breast feed the baby.

Fifteen of the forty-four (34\%) women belonging to the Kuppuswamy class III opted for breast-feeding, and 5 of the eighteen (28\%) women belonging to Kuppuswamy class IV opted for breast-feeding. These factors are indicative of the fact that parents are being more aware and conscious about prevention of transmitting the disease to their babies. But significantly, critical message of SAFE exclusive breastfeeding with ongoing antiretroviral therapy does not seem to impact the couples and families. The World Alliance for Breast feeding 
Action and World Health Organization (WHO) recommend, exclusive breast feeding for first six months of life in HIV infected mothers, unless replacement formula feeding is acceptable, feasible, affordable, sustainable and safe for the baby before that time..$^{5,11}$

WHO recommends avoidance of all breastfeeding by HIV-infected women, when these conditions are met. The HIV positive women are counselled throughout their antenatal period as a state policy about the implications of breast and formula feeds. Majority of HIV positive, urban lower middle class women opted for top feeding as it was acceptable, feasible, affordable, sustainable and safe. Larger studies on understanding of families of the affected women about issue of neonatal and infant feeding are required.

Infant deaths in exposed babies: Shapiro and Lockman state that even uninfected exposed babies of HIV positive mothers have higher mortality than those born to HIV negative mothers. ${ }^{12}$ In the babies that are topfed the mortality is higher due to exposure to other infections like diarrhoea. The Infants from our series who died in first six weeks were all topfed and were ineligible as per AFASS criteria except one. This highlights importance of adherence to breastfeeding especially when antiretroviral drugs are already being administered to the mother for prevention of neonatal infection.

\section{Limitations}

Our sample size is small and it is a single center study limited to urban population and tertiary center. Health services in rural and multi-tier systems should be studied to get a wider perspective of sociodemographic factors unique to those systems, concerning vertical HIV transmission. This study had a short duration of follow up. Longer follow up will give insights into feeding practices once the mother baby pairs are out of close surveillance.

\section{CONCLUSION}

- Social class and demographic factors play a vital role among the pregnant women in obtaining antenatal, intrapartum and postpartum care. Education empowers women with proper knowledge about infectivity of IHV.

- Antenatal period is the time when screening for communicable as well as non-communicable diseases is undertaken. This opportunity may be missed if the pregnant woman does not seek care. Patients who have early registration, are seen to have better feto-maternal outcome. This health seeking behavior is dependent on demographic factors and social support.

- Improved counseling, better outreach worker force and empathetic attitude towards patients reduce the dropout rates of treatment and follow up.
- Majority of HIV positive urban lower middle-class women opted for top feeding the baby, as they considered it an acceptable, feasible, affordable, sustainable and safe option. High neonatal mortality in these women means that babies died due to causes other than HIV. Counseling strategy may be looked into and long-term hand holding may be required in the women who choose top feeding, as risks of morbidity and mortality are unacceptably high in top fed babies, more so in economically disadvantaged class.

- Health systems need to take affirmative action in reaching all HIV positive pregnant women to offer them protective cover so that their own and their babies' lives are protected.

\section{ACKNOWLEDGEMENTS}

Authors acknowledge the kind cooperation of National AIDS Control Organisation, India

Funding: No funding sources

Conflict of interest: None declared

Ethical approval: The study was approved by the Institutional Ethics Committee

\section{REFERENCES}

1. Latest statistics on the status of the AIDS epidemic. UNAIDS. Available at http://www.unaids.org/en/ resources/fact-sheet.

2. HIV and AIDS estimates India 2015. UNAIDS Available at http://www.unaids.org/en/ regionscountries/countries/india.

3. Goswami S, Chakravorty PS. Prevention of parent to child transmission of HIV (PPTCT): an effort of 4 years in a tertiary centre. $\mathrm{J}$ Obstet Gynecol India. 2011;61(4):394-8.

4. Prevention of parent to child transmission (PPTCT) of HIV using multi drug anti-retroviral regimen in India. 2013. Available at http://www.indiahivinfo. naco.gov.in/sites/default/files/media-gallery/National _Guidelines_for_PPTCT.pdf

5. Counselling HIV-positive mothers about how to feed their babies using current HIV and infant feeding recommendations. Available at www.waba.org.my/whatwedo/hcp/pdf/hivkit4.pdf

6. Rajaraman D, Palmer N. Changing roles and responses of health care workers in HIV treatment and care. Trop Med Int Health. 2008;13(11):135763.

7. Joshi U, Patel S, Shah K, Oza U, Modi H. Studying PPTCT services, interventions, coverage and utilization in India. J Glob Infect Dis. 2011;3(4):3717.

8. Fabiani M, Nattabi B, Opio AA, Musinguzi J, Biryahwaho B, Ayella EO et al. A high prevalence of HIV-1 infection among pregnant women living in a rural district of north Uganda severely affected by 
civil strife. Trans R Soc Trop Med Hyg. 2006;100(6):586-93.

9. Ojieabu WA, Femi-Oyewo MN, Ojieabu CI. Impact of educational status on HIV/AIDS knowledge, attitude and misconceptions among pregnant women. Int J Biol Chem Sci. 2012;6(4):1582-92.

10. Vieira ACBC, Miranda AE, Vargas PRM de, Maciel ELN. HIV prevalence in pregnant women and vertical transmission in according to socioeconomic status, Southeastern Brazil. Rev Saude Publica. 2011;45(4):644-51.

11. HIV Transmission Through Breastfeeding. A review of available evidence. An Update from 2001-2007.
Available at http://www.who.int/nutrition/topics/ Paper_5_Infant_Feeding_bangkok.pdf.

12. Shapiro R, Lockman S. Mortality among HIVexposed infants: the first and final frontier. Clin Infect Dis. 2010;50(3):445-7.

Cite this article as: Samant PY, Puri JJ. Relevance of sociodemographic characteristics in care of HIV reactive pregnant women in the context of upscaled antiretrovial therapy in India. Int J Reprod Contracept Obstet Gynecol 2017;6:4016-22. 